\title{
Age at Menopause, Cause-Specific Mortality and Total Life Expectancy
}

\author{
Marlies E. Ossewaarde, ${ }^{*}$ Michiel L. Bots, ${ }^{*}$ André L. M. Verbeek, ${ }^{\prime}$ Petra H. M. Peeters, \\ Yolanda van der Graaf, ${ }^{*}$ Diederick E. Grobbee, " and Yvonne T. van der Schouw*
}

\begin{abstract}
Background: A later menopause has been associated with a decreased cardiovascular risk but with an increased risk for breast and endometrial cancer. The net effect on mortality is unclear. We determined the association of age at menopause with longevity and with the balance between cardiovascular and cancer mortality.

Methods: We analyzed data from a breast cancer screening cohort comprising 12,134 postmenopausal women followed for an average of 17 years. We used Cox proportional hazards models and life tables to calculate the life expectancy of an average Dutch woman at age 50 .

Results: During 204,024 person-years, there were 2607 deaths, of which 963 were due to cardiovascular diseases and 812 due to cancer. Ischemic heart disease risk decreased with a later menopause (hazard ratio $[\mathrm{HR}]=0.98$ per year; $95 \%$ confidence interval $=$ $0.96-0.99)$, but the risk of fatal uterine or ovarian cancer increased (1.07 per year; 1.01-1.12). A later menopause was associated with longer overall survival; HR for total mortality was 0.98 per year (0.97-0.99). Life expectancy in women with menopause after age 55 was 2.0 years longer than those with menopause before age 40 . Adjustment for potential confounders did not materially change the results.

Conclusions: Age-adjusted mortality is reduced 2\% with each increasing year of age at menopause. In particular, ischemic heart disease mortality is $2 \%$ lower. Although the risk of death from uterine or ovarian cancer is increased by $5 \%$, the net effect of a later menopause is an increased lifespan.
\end{abstract}

(Epidemiology 2005;16: 556-562)

Submitted 30 March 2004; final version accepted 7 February 2005

From the *Julius Center for Health Sciences and Primary Care, University Medical Center Utrecht, Utrecht, The Netherlands; and the †Department of Epidemiology, University of Nijmegen, The Netherlands.

e Supplemental material for this article is available with the online version of the journal at www.epidem.com.

Correspondence: Yvonne T. van der Schouw, Julius Center for Health Sciences and Primary Care, University Medical Center Utrecht, Room STR 6.133, PO Box 85500, 3508 GA Utrecht, The Netherlands. E-mail: y.t.vanderschouw@umcutrecht.nl.

Copyright (C) 2005 by Lippincott Williams \& Wilkins

ISSN: $1044-3983 / 05 / 1604-0556$

DOI: $10.1097 / 01 . e d e .0000165392 .35273 . d 4$
$\mathrm{T}$ he relation between late menopause and a reduced cardiovascular disease (CVD) risk is well established. ${ }^{1,2}$ Observational studies have shown a reduced risk of cardiovascular disease, ${ }^{1-4}$ fewer calcifications in the aorta ${ }^{5}$ and less extensive atherosclerosis ${ }^{6}$ in women with later menopause. Menopausal state has recently been added to the Framingham risk function for estimating absolute cardiovascular disease risk in women. ${ }^{7}$ Also, fracture risk decreases when menopause occurs later. ${ }^{8}$

In contrast, later menopause has been related to increased risk of breast cancer ${ }^{9,10}$ endometrial and ovarian cancer, and perhaps hepatocellular cancer. ${ }^{11-13}$ However, the risk of colorectal cancer appears decreased. ${ }^{14}$ These malignancies are common in Western societies.

Most studies have reported on the relation between age at menopause and cause-specific mortality. Little is known about the net effect of age at menopause on life expectancy. The objective of the present study was to determine the association of age at menopause with longevity, and to determine the balance between cardiovascular and cancer mortality at different ages at menopause using longitudinal data from a large Dutch breast cancer screening cohort.

\section{METHODS}

\section{Study Population}

Between December 1974 and September 1977, 14,701 (72\%) of the 20,555 women (age 48-68 years) living in Utrecht were enrolled in the Diagnostisch Onderzoek Mammacarcinoom cohort as part of a breast cancer screening program. Study procedures have been described in more detail elsewhere. ${ }^{15}$ Briefly, women were invited for several screening examinations, up to a maximum of 5. Information on smoking habits, medication and medical and reproductive history was collected through questionnaires. Information on age at menopause was missing for 982 women (7\%) and these women were excluded from this analysis. Users of postmenopausal hormone replacement therapy $(\mathrm{n}=1588)$ were also excluded, leaving 12,134 women for the analyses. 


\section{Variables}

Height and weight were measured at baseline and body mass index (BMI; $\mathrm{kg} / \mathrm{m}^{2}$ ) was calculated. We categorized menopause as (1) natural when menstrual bleeding had stopped spontaneously for at least 12 months, (2) due to hysterectomy when only the uterus was removed, (3) due to ovariectomy when the ovaries or the ovaries in combination with the uterus were removed, or (4) unknown. Hypertension was inferred from the reported use of antihypertensive medication. Similarly, women on oral antidiabetic drugs or insulin or a diabetes diet were classified as diabetic. Presence of cardiovascular disease was defined by self-reported use of medication for cardiovascular disease, including aminoglycosides, antiarrhythmic drugs, nitrates, other antianginal drugs, or anticoagulants. Oral contraceptive use was coded as "ever used" or "never used," because the number of women taking oral contraceptives was too small for detailed analysis. Parity and age at first delivery were combined in 1 variable with 3 categories: no children, children before or at the age of 24 , and children after the age of 24. Data on smoking were collected at the second screening examination ( 1 year after the first examination) and are therefore not known for women who did not attend the second screening examination $(\mathrm{n}=$ 2458).

\section{Assessment of Mortality}

The mean follow up \pm standard deviation (SD) was $17 \pm$ 5.1 years. There were 2607 deaths during 204,024 personyears; 963 were due to cardiovascular diseases, 812 were due to cancer, and 832 were due to other causes. At the end of follow up (1 January 1996), 1805 women (15\%) had moved outside the area and 7722 women $(64 \%)$ were still alive. Mortality follow up was more than $99 \%$ complete and women gave informed consent for participation. Approval was obtained from the Institutional Review Board of the University Medical Center Utrecht and women gave informed consent for participation.

The Utrecht Municipal Registry informed the investigators about places of residence and deaths of DOM-cohort members on a monthly basis. Causes of death were obtained from the woman's general practitioner and coded according to the ninth revision of the International Classification of Diseases (ICD-9). Codes of the various ICD classifications used for end point definition are presented in the Appendix (available with the electronic version of this article at www.epidem.com).

\section{Data Analysis}

Analyses were conducted for total mortality, cardiovascular mortality (ischemic heart disease mortality, cerebrovascular disease mortality, and mortality from stroke), and cancer mortality using Cox proportional hazard regression models. Death from other causes and loss to follow up due to moving outside Utrecht were considered censoring events.
Because mortality increases with age, all analyses were adjusted for age at entry. The association between age at menopause and mortality was analyzed with age at menopause as a continuous or as a categorized variable $(<40$, $40-44,45-49,50-54$, or $>55$ years). Women with menopause between 50 and 54 years of age were taken as a reference category. Results are presented as hazard ratios (HRs) with corresponding 95\% confidence intervals $(95 \%$ CIs). To control for potential confounding, the following factors were entered in a multivariate Cox proportional hazards model, first 1 by 1 and then all factors simultaneously: year of birth, occurrence of natural menopause, parity, age at first delivery, past use of oral contraceptives, hypertension, BMI, smoking, diabetes mellitus, or previous CVD. To evaluate whether some risk factors modify the association of age at menopause and (cause-specific) mortality risk, we performed stratified analyses with obesity (BMI $<30$ or BMI $\geq 30$ ), type of menopause (natural, hysterectomy, ovariectomy, unknown), age at entry ( $\leq 55$ or $>55$ years of age), and smoking (never, past, current $<10 /$ d, current $10-20 /$ d, current $>20 / d$ ) as distinguishing variables.

To study the association of age at menopause with longevity, a life table was constructed using a hypothetical population of women age 50 years. First, we applied Dutch national mortality risks to this population to obtain an estimate of longevity. Second, we divided the mortality risks into 3 categories: cardiovascular mortality, cancer mortality, and other mortality, based on the cause-specific proportions observed in our study. Then we estimated, for each menopause category, the life expectancy using the cause-specific mortality risks multiplied by the observed hazard ratio in our analyses. Finally, we calculated the difference in life expectancy between women having menopause at 55 years of age or older and women with menopause before age 40 .

\section{RESULTS}

Characteristics of the population are presented in Table 1. Mean \pm SD age at menopause was $49.0 \pm 4.5$ years (median 50 years); $78 \%$ of women had their menopause between 45 and 54 years of age. For never-smokers, mean age at menopause was $49.3 \pm 4.5$ years (median 50 years), for past smokers $48.5 \pm 4.9$ years (median 49 years), and for current smokers $48.5 \pm 4.6$ years (median 49 years). When stratified by presence of obesity (BMI $\geq 30 \mathrm{~kg} / \mathrm{m}^{2}$ ), mean age at menopause was $48.9 \pm 4.8$ years for obese women (median 50 years) and $49.0 \pm 4.5$ years for nonobese women (median 50 years).

A later menopause was associated with an age-adjusted decreased total mortality risk (Table 2), showing a linear trend $(\mathrm{HR}=0.98$ per year; $95 \% \mathrm{CI}=0.97-0.99)$. This result implies a $2 \%$ reduction in risk for each year menopause is delayed. A $2 \%$ reduced age-adjusted risk was also found for death from all cardiovascular disease $(0.98$ per year; $0.97-$ 
TABLE 1. Population Characteristics by Age at Menopause (Years)

\begin{tabular}{|c|c|c|c|c|c|c|}
\hline & \multicolumn{5}{|c|}{ Age at Menopause } & $\begin{array}{c}\text { All } \\
(\mathrm{n}=12,134)\end{array}$ \\
\hline Age at entry (years); mean \pm SD & $56.8 \pm 4.4$ & $57.3 \pm 4.4$ & $57.1 \pm 4.4$ & $57.5 \pm 4.1$ & $58.0 \pm 4.2$ & $57.4 \pm 4.3$ \\
\hline \multicolumn{7}{|l|}{ Type of menopause; \% } \\
\hline Natural & 46 & 60 & 80 & 92 & 92 & 83 \\
\hline Unknown & 12 & 9 & 4 & 2 & 3 & 4 \\
\hline Oral contraceptive use (ever use); \% & 0 & 3 & 5 & 7 & 8 & 6 \\
\hline Nulliparous; \% & 20 & 19 & 19 & 18 & 17 & 19 \\
\hline Age at first delivery $>24$ yr; $\%$ & 39 & 50 & 50 & 53 & 57 & 52 \\
\hline \multicolumn{7}{|l|}{ BMI $\left(\mathrm{kg} / \mathrm{m}^{2}\right)$} \\
\hline Never-smoker & 65 & 69 & 70 & 75 & 81 & 73 \\
\hline Past smoker & 1 & 3 & 1 & 1 & 2 & 2 \\
\hline \multicolumn{7}{|l|}{ Current smoker (no. cigarettes per day) } \\
\hline$<10$ & 10 & 11 & 11 & 10 & 10 & 11 \\
\hline $10-20$ & 19 & 13 & 13 & 11 & 7 & 12 \\
\hline$>20$ & 5 & 4 & 4 & 3 & 2 & 3 \\
\hline Hypertension present; \% & 15 & 13 & 14 & 15 & 18 & 15 \\
\hline Diabetes present; \% & 2 & 4 & 3 & 3 & 4 & 3 \\
\hline Previous cardiovascular disease present; \% & 8 & 6 & 5 & 5 & 5 & 5 \\
\hline
\end{tabular}

0.99). Among cardiovascular deaths, risk was reduced for ischemic heart diseases (0.98 per year; 0.96-0.99) and for stroke (0.94 per year; 0.89-1.00).

For total cancer mortality, the crude HR was 0.99 per year (0.97-1.00). This risk was unchanged after additional adjustment for smoking (0.99 per year; 0.98-1.01). An increased risk was observed with later age at menopause and mortality from uterine or ovarian cancer (1.07 per year; 1.01-1.12). When uterine and ovarian cancer were each considered separately, both risks increased with increasing age at menopause; however, because of small numbers, these cancers were combined. Age at menopause was not strongly associated with the risk of death from breast cancer (1.02 per year; 0.97-1.06), colorectal cancer (0.98 per year; 0.94$1.02)$, or total cerebrovascular disease (0.98 per year; $0.95-$ 1.01). Additional adjustment for smoking or exclusion of the smokers did not materially change these results. Additional adjustment for other potential confounding factors, subsequently or simultaneously, also left the results essentially unchanged (data not shown).

As demonstrated in Tables 3 and 4, the associations tended to be more pronounced for younger women. Hazard ratios for CVD tended to be lower in never-smoking women.
Type of menopause (natural menopause or not) did not affect the associations between age at menopause and cause-specific mortality.

The net effect of a later menopause is demonstrated in Figure 1. Life expectancy in women with a very late menopause ( $>55$ years) was 2.0 years longer compared with women who had an early menopause $(<40$ years) (adjusted for age differences at entry in the study).

\section{DISCUSSION}

In this prospective cohort study, a 1-year delay in menopause was associated with a $2 \%$ decreased risk of death from all causes. For cause-specific mortality, the most marked risk reductions were observed for ischemic heart disease $(2 \%)$. The risk of death from uterine or ovarian cancer increased $7 \%$ with each year of delay in menopause. The associations were most pronounced among younger women and leaner women. The net effect of a later menopause was an increased lifespan.

The prospective design of this study makes biased reporting of age at menopause unlikely. ${ }^{3}$ As demonstrated in previous reports, self-reported age at menopause and type of menopause are reasonably valid and reproducible. ${ }^{16,17}$ 


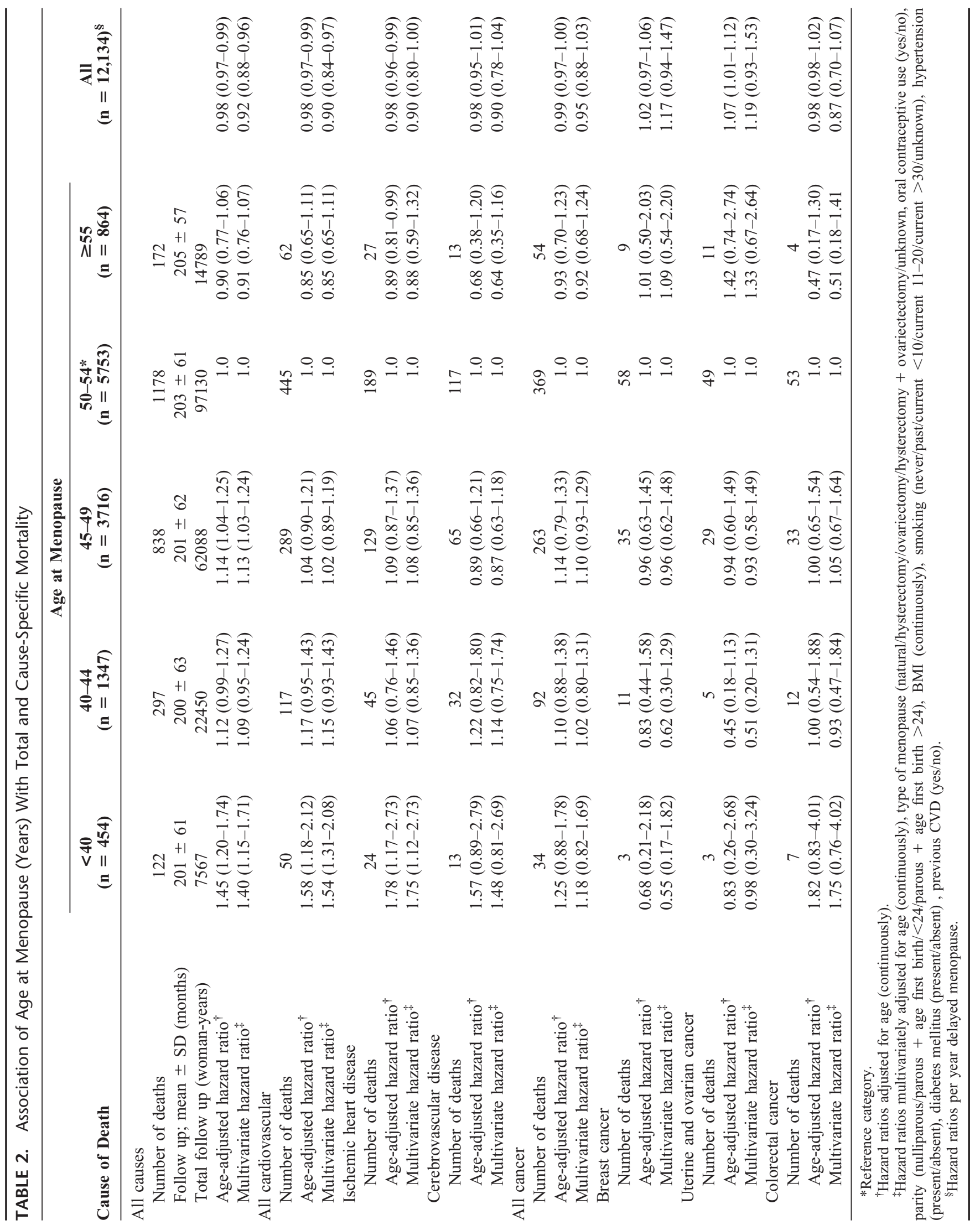


TABLE 3. Association* of Age at Menopause With Total Mortality and Cardiovascular Mortality, Stratified by Several Characteristics

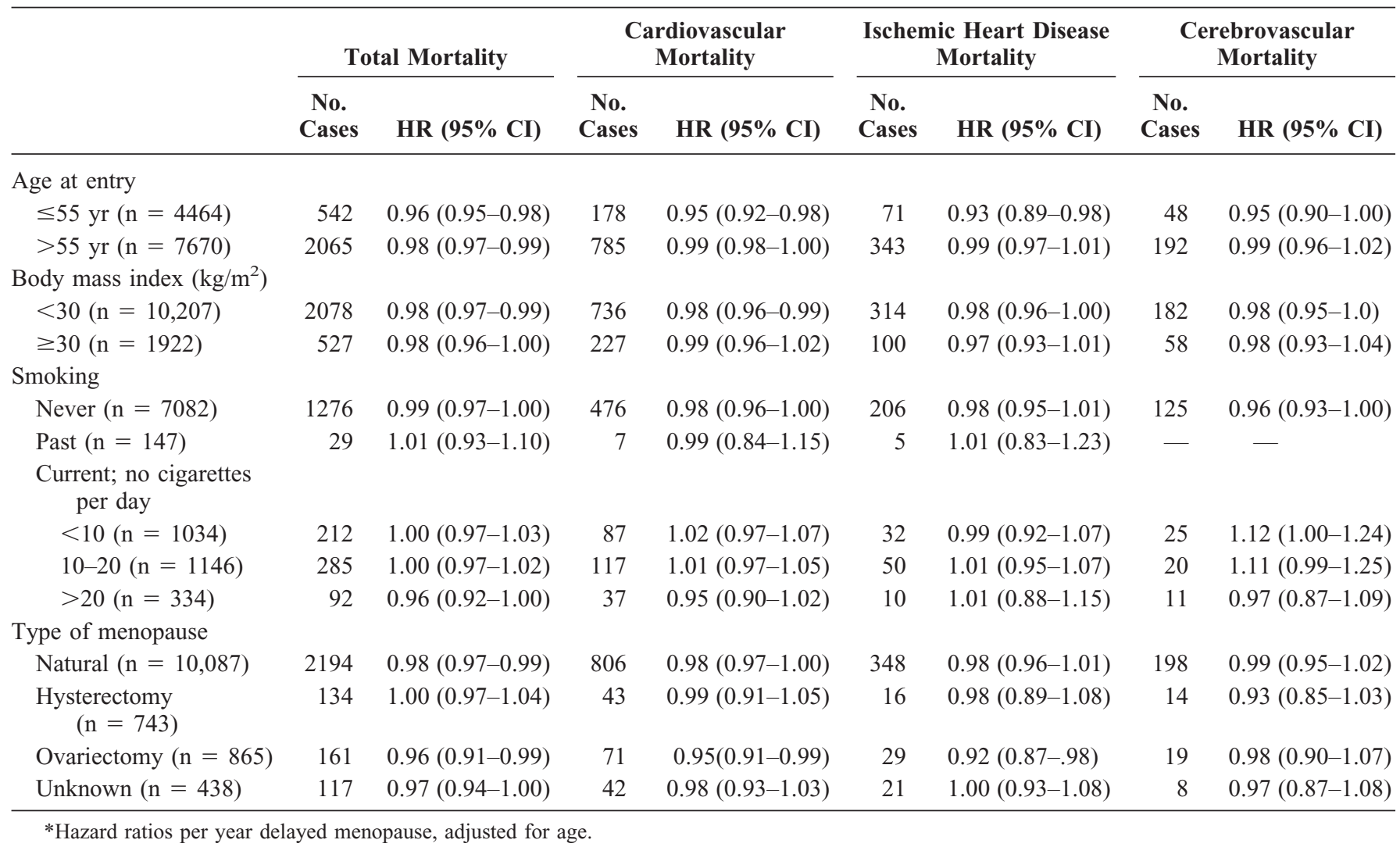

Smoking is a powerful risk factor for CVD and cancer, and is related to an earlier menopause. ${ }^{18}$ The mean age at menopause among current smokers in our cohort was 48.6 years, compared with 49.4 for never-smokers, making smoking a serious potential confounder. Additional adjustment for smoking or exclusion of smokers left the results essentially unchanged, suggesting that residual confounding by smoking is unlikely. When stratified according to smoking behavior, the associations tended to be more pronounced among neversmokers than among current and past smokers, which provides additional support for this reasoning.

Several other follow-up studies have reported an association between age at menopause and total mortality. ${ }^{19-21}$ Some of these studies were too small to explore causespecific mortality or effects of type of menopause. The present study largely confirms these findings and expands the available evidence by presenting precise estimates for causespecific mortality.

Most cohort studies have investigated the relation between age at menopause and the risk of specific diseases. A recent report from the Nurses' Health Study ${ }^{4}$ included 35,616 women without CVD at baseline, with natural menopause, and with no history of hormone replacement therapy use. The risk of (nonfatal) coronary heart disease (CHD; adjusted for age and smoking) increased 3\% per 1-year decrease in age at menopause, but risk of stroke was not affected. Both results are quite similar to our own. Their finding, however, was apparently confined to smoking women, in contrast to the results of our study. Other studies also support a cardioprotective effect of a later menopause. ${ }^{3,22-26}$ A stronger effect of age at menopause on CHD at younger ages (as we saw) has been reported by several other studies as well. ${ }^{2,3,22}$ This pattern may be due to cessation of exposure to potentially cardioprotective endogenous estrogens longer ago in these women. These differences could also relate to differences in the distributions of age at menopause as well as the proportions with surgical versus natural menopause.

Some studies observed a U-shaped association, with an increased risk of CVD in women who had a very late menopause $\left(>55\right.$ years). ${ }^{19,25}$ A few studies observed the increased risk of CHD after menopause to be stronger in or even restricted to women with a surgical menopause. ${ }^{24,26}$ Use of estrogens appeared to prevent this increased risk. ${ }^{24} \mathrm{We}$ did not confirm this finding in the present study. 
TABLE 4. Association* of Age at Menopause With Cancer Mortality, Stratified by Several Characteristics

\begin{tabular}{|c|c|c|c|c|c|c|c|c|}
\hline & \multicolumn{2}{|c|}{ All Cancers } & \multicolumn{2}{|c|}{ Breast Cancer } & \multicolumn{2}{|c|}{$\begin{array}{c}\text { Uterine and Ovarian } \\
\text { Cancer }\end{array}$} & \multicolumn{2}{|c|}{ Colorectal Cancer } \\
\hline & $\begin{array}{l}\text { No. } \\
\text { Cases }\end{array}$ & HR (95\% CI) & $\begin{array}{l}\text { No. } \\
\text { Cases }\end{array}$ & HR (95\% CI) & $\begin{array}{l}\text { No. } \\
\text { Cases }\end{array}$ & HR $(95 \%$ CI $)$ & $\begin{array}{l}\text { No. } \\
\text { Cases }\end{array}$ & HR $(95 \%$ CI $)$ \\
\hline \multicolumn{9}{|l|}{ Age at entry } \\
\hline $\begin{array}{l}\leq 55 \mathrm{yr}(\mathrm{n}=4464) \\
>55 \mathrm{yr}(\mathrm{n}=7670)\end{array}$ & 211 & $0.98(0.96-1.01)$ & 541 & $1.03(0.96-1.10)$ & 22 & $1.11(1.00-1.24)$ & 21 & $0.93(0.86-1.01)$ \\
\hline$<30(\mathrm{n}=10,207)$ & 667 & $0.99(0.97-1.00)$ & 91 & $1.02(0.97-1.07)$ & 79 & $1.06(1.00-1.12)$ & 89 & $0.98(0.94-1.03)$ \\
\hline$\geq 30(\mathrm{n}=1922)$ & 145 & $0.99(0.95-1.02)$ & 25 & $1.00(0.92-1.08)$ & 18 & $1.09(0.97-1.22)$ & 20 & $0.96(0.88-1.05)$ \\
\hline \multicolumn{9}{|l|}{ Smoking } \\
\hline Never $(\mathrm{n}=7082)$ & 412 & $1.00(0.98-1.02)$ & 68 & $0.99(0.94-1.04)$ & 53 & $1.09(1.02-1.17)$ & 60 & $1.00(0.94-1.06)$ \\
\hline Past $(\mathrm{n}=147)$ & 15 & $0.99(0.89-1.11)$ & 2 & $1.18(0.82-1.70)$ & 2 & $1.11(0.79-1.55)$ & 2 & $0.85(0.65-1.13)$ \\
\hline $10-20(\mathrm{n}=1146)$ & 91 & $0.98(0.94-1.02)$ & 10 & $1.18(0.98-1.42)$ & 9 & $1.18(0.97-1.42)$ & 7 & $0.85(0.76-0.95)$ \\
\hline$>20(\mathrm{n}=334)$ & 29 & $0.97(0.91-1.05)$ & 2 & $0.87(0.71-1.06)$ & 2 & $1.03(0.75-1.41)$ & 5 & $1.03(0.84-1.25)$ \\
\hline \multicolumn{9}{|l|}{ Type of menopause } \\
\hline Natural $(\mathrm{n}=10,087)$ & 674 & $0.99(0.97-1.01)$ & 94 & $1.02(0.96-1.07)$ & 89 & $1.07(1.01-1.13)$ & 88 & $0.99(0.94-1.04)$ \\
\hline $\begin{array}{l}\text { Hysterectomy } \\
\qquad(\mathrm{n}=743)\end{array}$ & 50 & $1.04(0.98-1.10)$ & 9 & $1.24(1.08-1.44)$ & 3 & $1.07(0.84-1.35)$ & 9 & $0.96(0.84-1.09)$ \\
\hline Ovariectomy $(\mathrm{n}=865)$ & 50 & $0.96(0.92-1.01)$ & 7 & $0.94(0.82-1.08)$ & 2 & $1.18(0.89-1.59)$ & 8 & $1.04(0.91-119)$ \\
\hline Unknown $(\mathrm{n}=438)$ & 38 & $0.95(0.91-1.00)$ & 6 & $0.96(0.85-1.10)$ & 3 & $0.87(0.75-1.02)$ & 4 & $0.93(0.80-1.08)$ \\
\hline
\end{tabular}

*Hazard ratios per year delayed menopause, adjusted for age.

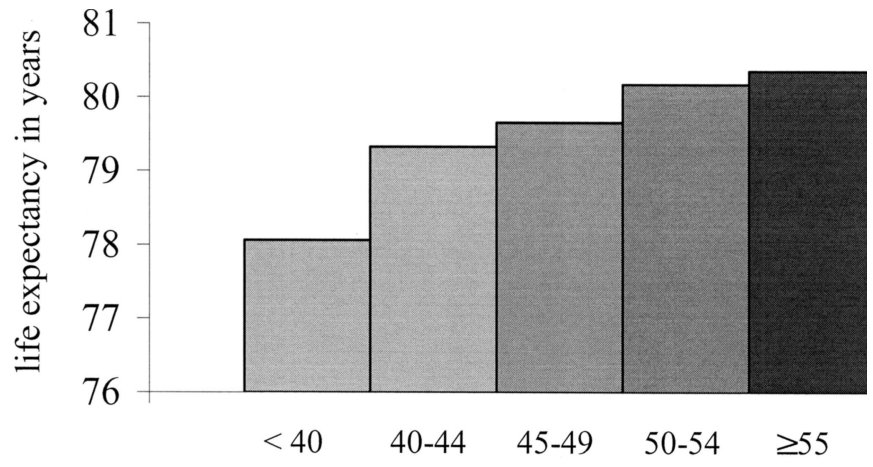

FIGURE 1. Life expectancy by age at menopause (years).

Most of the evidence regarding estrogens and cancer risk deals with exogenous estrogens and suggests an increased risk of (fatal) breast and endometrial cancer among hormone replacement therapy users. ${ }^{27,28}$ However, several studies indirectly provide support for an association between exposure to endogenous estrogens and an increased risk of breast cancer, endometrial cancer, and ovarian cancer. ${ }^{10,12}$ Women who subsequently developed breast cancer are reported to have $15 \%$ higher mean serum concentrations of estradiol compared with their control counterparts. ${ }^{29}$ The magnitude of the increase in risk of breast cancer associated with each year of use of hormone replacement therapy appears to be roughly equivalent to the increase associated with delaying menopause by 1 year. ${ }^{9}$ Our results indicate that, overall, women with a late menopause live 2 years longer than women with an early menopause. This difference is comparable to previous estimates ${ }^{30}$ and, given the magnitude, may justify further studies on modifiable determinants of age at menopause.

\section{REFERENCES}

1. de Kleijn MJ, van der Schouw YT, Verbeek AL, et al. Endogenous estrogen exposure and cardiovascular mortality risk in postmenopausal women. Am J Epidemiol. 2002;155:339-345.

2. van der Schouw YT, van der Graaf Y, Steyerberg EW, et al. Age at menopause as a risk factor for cardiovascular mortality. Lancet. 1996; 347:714-718.

3. Jacobsen BK, Nilssen S, Heuch I, et al. Does age at natural menopause affect mortality from ischemic heart disease? J Clin Epidemiol. 1997; 50:475-479.

4. $\mathrm{Hu}$ FB, Grodstein F, Hennekens CH, et al. Age at natural menopause and risk of cardiovascular disease. Arch Intern Med. 1999;159: $1061-1066$

5. Witteman JCM, Grobbee DE, Kok FJ, et al. Increased risk of atherosclerosis in women after the menopause. BMJ. 1989;298:642-644.

6. Joakimsen O, Bønaa KH, Stensland-Bugge E, et al. Population-based 
study of age at menopause and ultrasound assessed carotid atherosclerosis: the Tromso Study. J Clin Epidemiol. 2000;53:525-530.

7. d'Agostino RB, Russell MW, Huse DM, et al. Primary and subsequent coronary risk appraisal: new results from the Framingham study. Am Heart J. 2000;139:272-281.

8. Van Der Voort DJ, Van Der Weijer PH, Barentsen R. Early menopause: increased fracture risk at older age. Osteoporos Int. 2003;14:525-530.

9. Collaborative Group on Hormonal Factors in Breast Cancer.Breast cancer and hormone replacement therapy: collaborative reanalysis of data from 51 epidemiological studies of 52,705 women with breast cancer and 108,411 women without breast cancer. Lancet. 1997;350: $1047-1059$.

10. Monninkhof EM, van der Schouw YT, Peeters PH. Early age at menopause and breast cancer: are leaner women more protected? A prospective analysis of the Dutch DOM cohort. Breast Cancer Res Treat. 1999;55:285-291.

11. de Graaff J, Stolte LA. Age at menarche and menopause of uterine cancer patients. Eur J Obstet Gynecol Reprod Biol. 1978;8:187-193.

12. Franceschi S, La Vecchia C, Booth M, et al. Pooled analysis of 3 European case-control studies of ovarian cancer: II. Age at menarche and at menopause. Int J Cancer. 1991;49:57-60.

13. Mucci LA, Kuper HE, Tamimi R, et al. Age at menarche and age at menopause in relation to hepatocellular carcinoma in women. BJOG. 2001;108:291-294.

14. van Wayenburg CA, van der Schouw YT, van Noord PA, et al. Age at menopause, body mass index, and the risk of colorectal cancer mortality in the Dutch Diagnostisch Onderzoek Mammacarcinoom (DOM) cohort. Epidemiology. 2000;11:304-308.

15. de Waard F, Collette HJ, Rombach JJ, et al. The DOM project for the early detection of breast cancer, Utrecht, The Netherlands. J Chronic Dis. 1984;37:1-44.

16. den Tonkelaar I. Validity and reproducibility of self-reported age at menopause in women participating in the DOM-project. Maturitas. 1997;27:117-123.

17. Colditz GA, Stampfer MJ, Willett WC, et al. Reproducibility and validity of self-reported menopausal status in a prospective cohort study. Am J Epidemiol. 1987;126:319-325.

18. McKinlay SM, Bifano NL, McKinlay JB. Smoking and age at menopause in women. Ann Intern Med. 1985;103:350-356.

19. Snowdon DA, Kane RL, Beeson WL, et al. Is early menopause a biological marker of health and aging? Am J Public Health. 1989;79: 709-714.

20. Cooper GS, Sandler DP. Age at natural menopause and mortality. Ann Epidemiol. 1998;8:229-235.

21. Jacobsen BK, Heuch I, Kvale G. Age at natural menopause and all-cause mortality: a 37-year follow-up of 19,731 Norwegian women. $\mathrm{Am} \mathrm{J}$ Epidemiol. 2003;157:923-929.

22. Kannel WB, Hjortland MC, McNamara PM, et al. Menopause and the risk of cardiovascular disease: the Framingham study. Ann Intern Med. 1976;85:447-452.

23. Rosenberg L, Hennekens CH, Rosner B, et al. Early menopause and the risk of myocardial infarction. Am J Obstet Gynecol. 1981;139:47-51.

24. Colditz GA, Willett WC, Stampfer MJ, et al. Menopause and the risk of coronary heart disease in women. $N$ Engl J Med. 1987;316:1105-1110.

25. Jacobsen BK, Knutsen SF, Fraser GE. Age at natural menopause and total mortality and mortality from ischemic heart disease: the Adventist Health Study. J Clin Epidemiol. 1999;52:303-307.

26. Cooper GS, Ephross SA, Weinberg CR, et al. Menstrual and reproductive risk factors for ischemic heart disease. Epidemiology. 1999;10:255-259.

27. Beral V, Banks E, Reeves G, et al. Use of HRT and the subsequent risk of cancer. J Epidemiol Biostat. 1999;4:191-210.

28. Rossouw JE, Anderson GL, Prentice RL, et al. Risks and benefits of estrogen plus progestin in healthy postmenopausal women: principal results from the Women's Health Initiative randomized controlled trial. JAMA. 2002;288:321-333.

29. Thomas HV, Reeves GK, Key TJ. Endogenous estrogen and postmenopausal breast cancer: a quantitative review. Cancer Causes Control. 1997;8:922-928.

30. Snowdon DA. Early natural menopause and the duration of postmenopausal life. Findings from a mathematical model of life expectancy. J Am Geriatr Soc. 1990;38:402-408. 